\section{Original Article}

Korean J Transplant 2020;34:178-184 https://doi.org/10.4285/kjt.2020.34.3.178

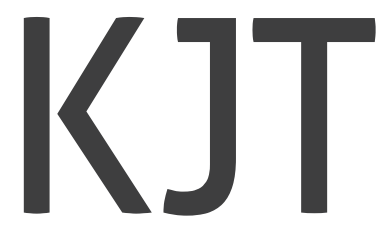

pISSN 2671-8790

elSSN 2671-8804

\title{
Korea-nationwide incidence of pediatric deceased donors and single-institutional status of liver transplantation using pediatric donor liver grafts
}

\author{
Jung-Man Namgung ${ }^{1}$, Shin Hwang ${ }^{1}$, Chul-Soo Ahn ${ }^{1}$, Ki-Hun Kim', Deok-Bog Moon', \\ Tae-Yong Ha ${ }^{1}$, Gi-Won Song ${ }^{1}$, Dong-Hwan Jung ${ }^{1}$, Gil-Chun Park ${ }^{1}$, Dea-Yeon Kim', \\ Kyung Mo Kim², Seak Hee Oh${ }^{2}$, Sung-Gyu Lee ${ }^{1}$
}

\footnotetext{
${ }^{1}$ Department of Surgery, Asan Medical Center, University of Ulsan College of Medicine, Seoul, Korea

${ }^{2}$ Department of Pediatrics, Asan Medical Center, University of Ulsan College of Medicine, Seoul, Korea
}

Received July 16, 2020
Revised August 17, 2020
Accepted August 17, 2020

Corresponding author: Shin Hwang Department of Surgery, Asan Medical Center, University of Ulsan College of Medicine, 88 Olympic-ro 43-gil, Songpagu, Seoul 05505, Korea

Tel: +82-2-3010-3930

Fax: +82-2-3010-6701

E-mail: shwang@amc.seoul.kr

(c) The Korean Society for Transplantation This is an Open Access article distributed under the terms of the Creative Commons Attribution Non-Commercial License (http://creativecommons.org/licenses/ by-nc/4.0/) which permits unrestricted non-commercial use, distribution, and reproduction in any medium, provided the original work is properly cited.
Background: The present study intended to investigate the allocation status of pediatric deceased donor liver allografts. We analyzed the incidence of pediatric deceased donors in the Korean Network for Organ Sharing (KONOS) database and single-institutional status of liver transplantation (LT) using pediatric donors.

Methods: We assessed the nationwide incidence of pediatric donors aged $\leq 15$ years and conducted single-center analysis of LT using pediatric donors.

Results: Between 2010 and 2019, pediatric donors aged $\leq 15$ years accounted for 171 out of 4,395 donors (3.9\%) in the KONOS database and 31 out of 640 liver donors (4.8\%) in Asan Medical Center (AMC) database. In AMC, 11 (35.5\%) and 20 (64.5\%) grafts were allocated to pediatric recipients aged $\leq 15$ years and adult recipients aged $\geq 19$ years, respectively. All nine livers from donors aged $\leq 5$ years were implanted in pediatric recipients aged $\leq 5$ years. From 21 donors aged $\geq 9$ years, 16 whole liver grafts and four split extended right liver grafts were implanted in 20 adult recipients and two split left lateral section grafts were implanted in two pediatric recipients. Four split liver grafts were implanted in other institutions. The overall patient survival rates at 1,3 , and 5 years were $90.9 \%, 80.8 \%$, and $80.8 \%$, respectively in pediatric-to-pediatric LT group and $69.6 \%$, $58.4 \%$, and $58.4 \%$, respectively in pediatric-to-adult $L T$ group $(P=0.21)$.

Conclusions: More than half of the pediatric donor livers were allocated to adult patients. Recipient criteria for allocation of liver allografts from pediatric donors need revision for children on pediatric LT waitlist.

Keywords: Donor age; Pediatric donor; Deceased donor liver transplantation; Infant; Split liver transplantation

\section{INTRODUCTION}

Liver transplantation (LT) is an effective treatment for pa- tients with end-stage liver disease due to its improved outcomes and broadening spectrum of indications. Shortage of organ donors and increased demand for LT have led to 


\section{HIGHLIGHTS}

- We analyzed the incidence of pediatric deceased donors in Korean Network for Organ Sharing (KONOS) database and the single-institutional status of liver transplantation using pediatric donors.

- The study results showed that over half of the pediatric donor livers were allocated to adult patients.

- The recipient criteria for allocation of livers from pediatric donors should be revised to facilitate the special needs of children on the pediatric liver transplantation waitlist.

widening of concepts to increase the availability of liver grafts for LT. Even though old and marginal liver donors, living donors, and domino procedures have been accepted, a profound donor organ shortage is still encountered.

For pediatric patients, LT with size-matched whole liver allografts from pediatric donors would be ideal. However, a considerable proportion of pediatric donor liver allografts have been implanted in adult patients [1-3]. Moreover, the availability of detailed information regarding graft allocation is limited in Korea [4]. Thus, there is an essential need to analyze the allocation status of pediatric deceased donor liver allografts in Korea. We investigated the incidence of pediatric deceased donors in the Korean Network for Organ Sharing (KONOS) database and the status of LT using pediatric donors in a high-volume LT center.

\section{METHODS}

The study protocol was approved by the Institutional Review Board of Asan Medical Center (IRB No. 2020-0857). The requirement for informed consent was waived by the Review Board due to the retrospective nature of this study. This study was performed in accordance with the ethical guidelines of the World Medical Association Declaration of Helsinki 2013.

\section{Study Design}

The purpose of this study was to investigate the allocation status of pediatric deceased donor liver allografts. This study comprised of two parts. The first part consisted of an assessment of the nationwide incidence of pediatric donors in Korea using the KONOS database. The second part consisted of a retrospective single-center analysis of LT using pediatric donors.

The study period was set between January 2010 and December 2019 for both parts of this study. We defined pediatric donors as donors aged $\leq 15$ years. The recipients were divided into the pediatric-to-pediatric LT group (recipients aged $\leq 15$ years) and the pediatric-to-adult LT group (recipients aged $\geq 19$ years). Post-transplant outcomes of the two groups were compared. The recipients in this study were followed up until May 2020.

\section{Statistical Analysis}

The numerical data were presented as mean \pm standard deviation. The continuous variables were compared using Student t-test. The incidence variables were compared using the chi-square test and the Fisher's exact test. The survival rates were estimated using the Kaplan-Meier method and compared using a log-rank test. A P-value $<0.05$ was considered statistically significant. Statistical analyses were performed using IBM SPSS ver. 22 (IBM Corp., Armonk, NY, USA).

\section{RESULTS}

\section{Incidence of Pediatric Deceased Donors in the KONOS Database}

During the 10-year study period, the total number of all deceased organ donors was 4,395. Among these, 171 (3.9\%) were pediatric donors aged $\leq 15$ years. The distribution of donors according to age is depicted in Fig. 1.

\section{Institutional Allocation Status of Pediatric Liver Allografts} to Pediatric and Adult Patients

During the 10-year study period, 640 deceased donor liver transplantations (DDLTs) were performed at our institution and $31(4.8 \%)$ DDLTs used pediatric donor liver allografts (Fig. 2). Among these 31 cases, there were 11 cases (35.5\%) of pediatric-to-pediatric DDLT including one case of multivisceral transplantation and 20 cases (64.5\%) of pediatric-to-adult DDLT including one case of liver-lung transplantation. All whole liver grafts from nine donors aged $\leq 5$ years were implanted in pediatric recipients aged $\leq 5$ years as whole liver grafts $(n=8)$ and multivisceral transplantation $(n=1)$. The mean weight of liver grafts was $451.3 \pm 111.4 \mathrm{~g}$ (range, $245-615 \mathrm{~g}$ ) and the graft-recipi- 

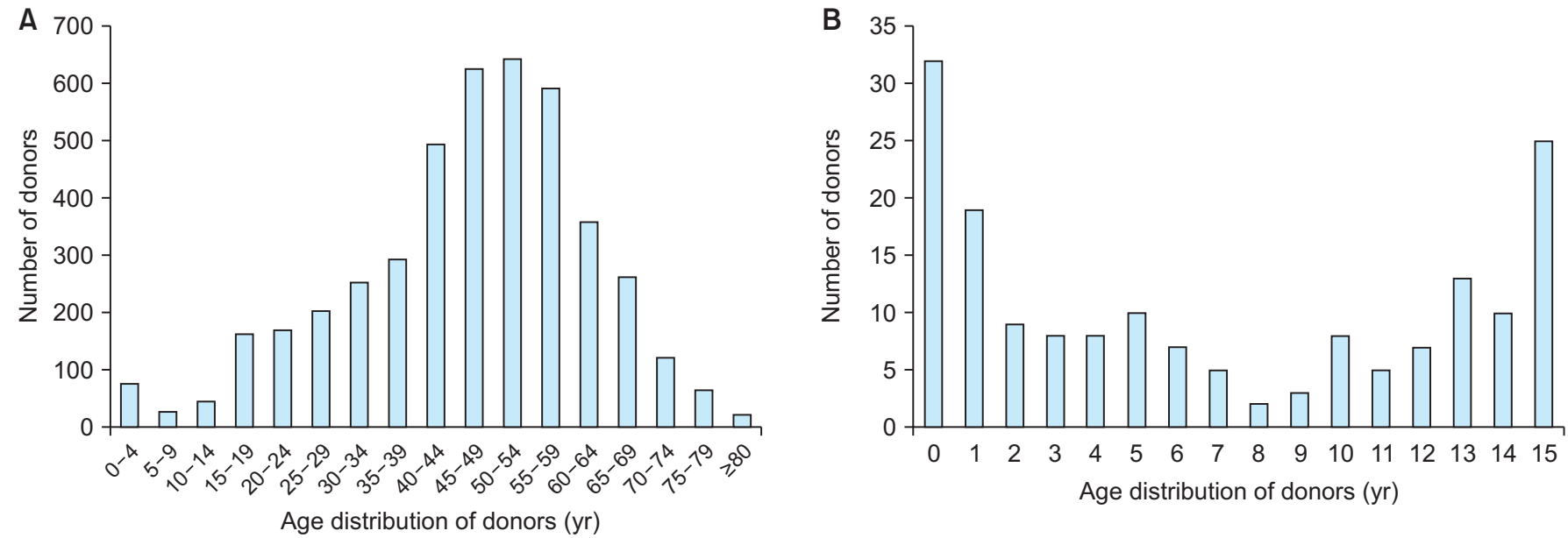

Fig. 1. Age distribution of deceased organ donors from January 2010 to December 2019 in Korea. (A) Age distribution of all donors in 5-year intervals. (B) Age distribution of pediatric donors aged up to 15 years in 1-year intervals.
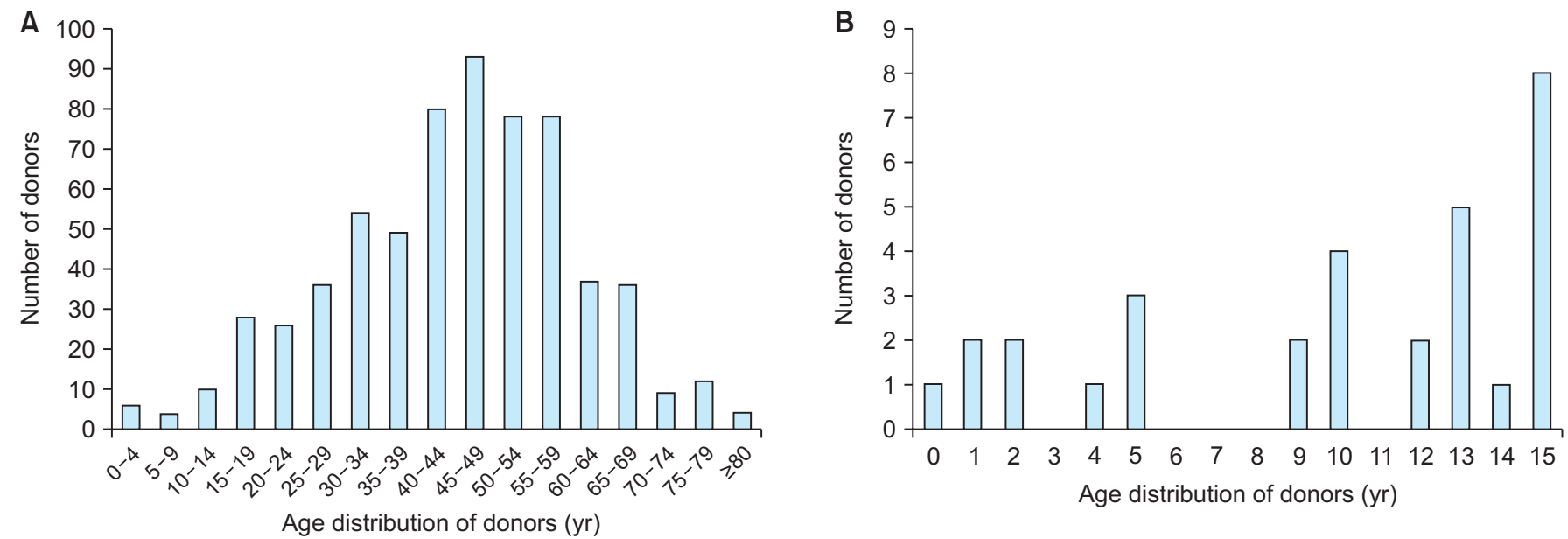

Fig. 2. Age distribution of deceased liver donors used for liver transplantation from January 2010 to December 2019 at Asan Medical Center. (A) Age distribution of all donors in 5-year intervals. (B) Age distribution of pediatric donors aged up to 15 years in 1-year intervals.

ent weight ratio (GRWR) was $3.83 \% \pm 1.18 \%$ (range, 2.34 $5.75 \%)$.

From 21 donors aged $\geq 9$ years, 16 whole liver grafts and four split extended right liver grafts were implanted in 20 adult recipients and two split left lateral section grafts were implanted in two pediatric recipients. One split extended right liver graft and three split left lateral section grafts were implanted in other institutions. The mean weight of liver grafts and the GRWR were 1,233.0 \pm 301.3 g (range, $596-1,620 \mathrm{~g}$ ) and $2.08 \% \pm 0.48 \%$ (range, $1.15 \%-$ $2.84 \%$ ), respectively in 16 adult whole liver recipients; $919.3 \pm 135.3 \mathrm{~g}$ (range, $800-1070 \mathrm{~g}$ ) and $1.62 \% \pm 0.29 \%$ (range, $1.23 \%-1.89 \%$ ), respectively in four adult split liv- er recipients; and $361.5 \pm 68.6 \mathrm{~g}$ (range, $313-410 \mathrm{~g}$ ) and $2.90 \% \pm 0.85 \%$ (range, $2.30 \%-3.50 \%$ ), respectively in two pediatric split liver recipients.

\section{Outcomes of Pediatric and Adult DDLTs Using Pediatric Liver Allografts}

The donor and recipient characteristics of the two groups are presented in Table 1. DDLTs using pediatric liver grafts included primary DDLTs in 26 patients and retransplantations in five patients. In-hospital mortality occurred in one case $(9.1 \%)$ of pediatric-to-pediatric DDLT and in four cases $(20.0 \%)$ of pediatric-to-adult DDLT. Graft failure was the cause of in-hospital mortality in the case of pe- 
Table 1. Comparison of patient profiles

\begin{tabular}{|c|c|c|c|}
\hline Variable & $\begin{array}{l}\text { Pediatric-to-pediatric deceased } \\
\text { donor liver transplantation }\end{array}$ & $\begin{array}{l}\text { Pediatric-to-adult deceased donor } \\
\text { liver transplantation }\end{array}$ & P-value \\
\hline No. of patients & 11 & 20 & - \\
\hline Recipient sex (male:female) & $7: 4$ & $14: 6$ & $<0.001$ \\
\hline Recipient age (yr) & $3.0 \pm 1.8$ & $50.2 \pm 13.6$ & $<0.001$ \\
\hline Primary disease & & & NA \\
\hline HBV-LC & 0 & 11 & \\
\hline HCV-LC & 0 & 1 & \\
\hline ALD & 0 & 3 & \\
\hline Biliary atresia & 3 & 0 & \\
\hline Metabolic disease & 3 & 0 & \\
\hline Retransplantation & 2 & 3 & \\
\hline Others & 3 & 2 & \\
\hline Recipient ABO blood group & & & NA \\
\hline A & 4 & 8 & \\
\hline B & 2 & 4 & \\
\hline 0 & 2 & 7 & \\
\hline$A B$ & 3 & 1 & \\
\hline \multicolumn{4}{|c|}{ Preoperative laboratory findings } \\
\hline Total bilirubin (mg/dL) & $7.1 \pm 6.6$ & $20.9 \pm 15.3$ & 0.003 \\
\hline Serum creatinine $(\mathrm{mg} / \mathrm{dL})$ & $0.42 \pm 0.39$ & $1.74 \pm 1.67$ & 0.014 \\
\hline Prothrombin time (INR) & $1.55 \pm 0.68$ & $2.40 \pm 1.01$ & 0.009 \\
\hline PELD/MELD score & $14.1 \pm 5.8$ & $30.2 \pm 9.4$ & $<0.001$ \\
\hline Donor sex (male:female) & $7: 4$ & $9: 11$ & 0.98 \\
\hline Donor age (yr) & $4.7 \pm 3.7$ & $12.6 \pm 2.3$ & $<0.001$ \\
\hline Graft type & & & 0.90 \\
\hline Whole liver & 9 & 16 & \\
\hline Split right liver & 2 & 4 & \\
\hline Graft weight (g) & $435.0 \pm 108.3$ & $1170.3 \pm 301.9$ & $<0.001$ \\
\hline Graft-recipient weight ratio & $3.67 \pm 1.15$ & $1.93 \pm 0.47$ & $<0.001$ \\
\hline \multicolumn{4}{|l|}{ Ischemic time } \\
\hline Cold & $279.2 \pm 120.7$ & $267.5 \pm 118.4$ & 0.79 \\
\hline Warm & $46.1 \pm 13.0$ & $48.1 \pm 13.5$ & 0.64 \\
\hline
\end{tabular}

Values are presented as number or mean \pm standard deviation.

NA, not available; HBV-LC, hepatitis B virus-associated liver cirrhosis; HCV-LC, hepatitis C virus-associated liver cirrhosis; ALD, alcoholic liver disease; INR, international normalization ratio; PELD, pediatric end-stage liver disease; MELD, model for end-stage liver disease.

diatric-to-pediatric DDLT. In-hospital mortality following pediatric-to-adult DDLT was due to sepsis in two patients, intracranial hemorrhage in one patient, and pulmonary thromboembolism in one patient. Severe early graft dysfunction did not occur in these early mortality cases. The causes of late patient mortality were multi-organ failure in one case of pediatric-to-pediatric DDLT; and graft-versushost disease in one case, pneumonia in one case, chronic rejection in one case, and recurrence of hepatocellular car- cinoma in one case of pediatric-to-adult DDLT.

The graft survival rates at 1,3 , and 5 years were $81.8 \%$, $81.8 \%$, and $81.8 \%$, respectively in the pediatric-to-pediatric DDLT group and $69.6 \%, 58.4 \%$, and $58.4 \%$, respectively in the pediatric-to-adult DDLT group $(\mathrm{P}=0.27)$ (Fig. 3A). There was only one case of pediatric liver retransplantation using a living donor liver graft following multivisceral transplantation at the third post-transplant day [5]. The overall patient survival rates at 1,3 , and 5 years were $90.9 \%, 80.8 \%$, 

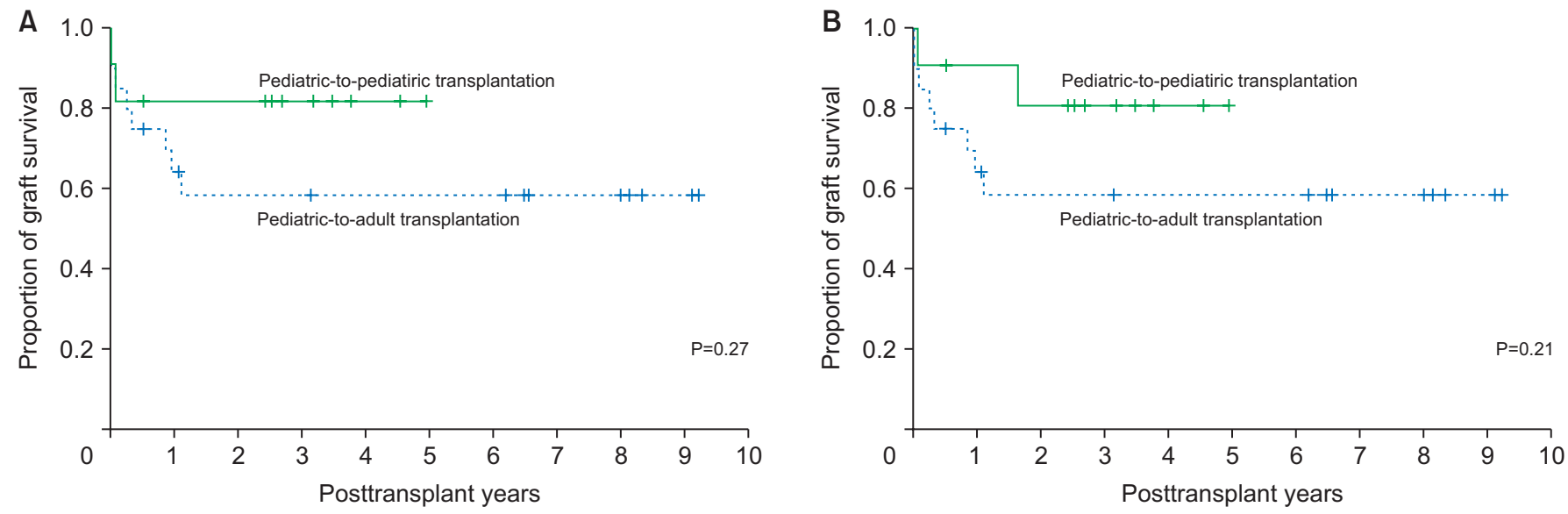

Fig. 3. Comparison of graft survival (A) and overall patient survival (B) outcomes according to recipient age.

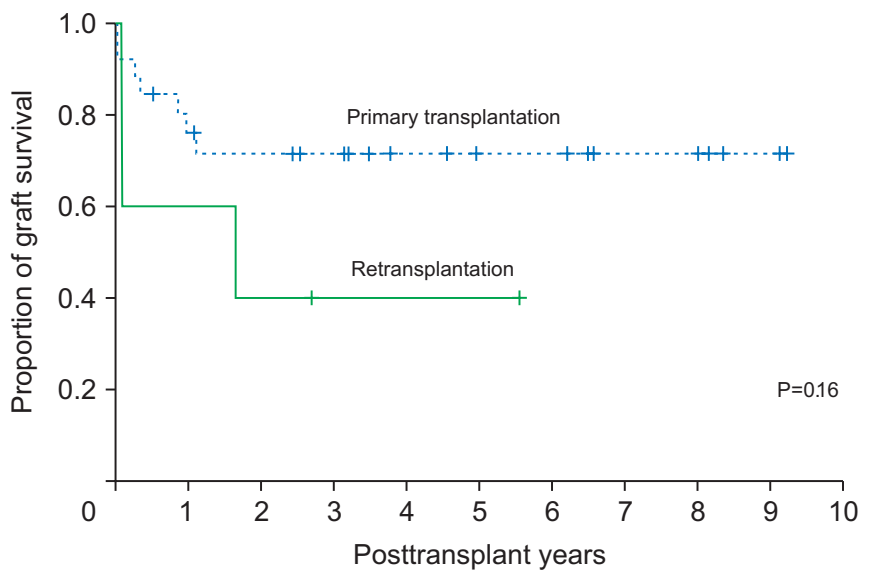

Fig. 4. Comparison of overall patient survival outcomes according to primary deceased donor liver transplantation and retransplantation.

and $80.8 \%$, respectively in the pediatric-to-pediatric DDLT group and $69.6 \%, 58.4 \%$, and $58.4 \%$, respectively in the pediatric-to-adult DDLT group ( $\mathrm{P}=0.21$ ) (Fig. 3B).

Retransplantation cases showed inferior survival outcomes when compared with primary DDLT with pediatric liver grafts (Fig. 4). However, the difference was not statistically significant $(P=0.16)$, which may be attributed to the small sample size.

\section{DISCUSSION}

In Korea, 4,395 cases of deceased donors were reported during the 10-year period from 2010 to 2019. Among these, 171 (3.9\%) were pediatric donors aged $\leq 15$ years. In our institutional experience of DDLT during the same study period, there were 31 (4.8\%) pediatric donors aged $\leq 15$ years among 640 deceased donors used for DDLT. Among the 31 pediatric donor liver allografts, nine whole liver grafts were implanted in pediatric recipients, 16 whole liver grafts were implanted in adult recipients, and six split liver grafts were implanted in two pediatric patients and in four adult patients. Four split liver grafts were implanted in other institutions. Liver splitting was performed in five donors and these 10 split liver grafts were implanted in five pediatric patients and in five adult patients. Thus, livers from 31 pediatric donors were used for 14 pediatric patients and 21 adult patients. More than half of the pediatric donor liver grafts were allocated to adult patients probably due to donor-recipient body weight matching and lack of pediatric patients with high priority on the pediatric waiting list.

Pediatric donors aged up to 5 years usually have body weights below $20 \mathrm{~kg}$. Liver allografts from these donors cannot be used for adult patients. Thus, all allografts from such donors were allocated to body weight-matched pediatric patients. According to the Korean standardized growth patterns of children, the 50th percentiles of body weight at 60 months, 120 months, and 180 months are $19.0 \mathrm{~kg}, 35.5 \mathrm{~kg}$, and $60.1 \mathrm{~kg}$, respectively. Thus, pediatric donors aged over 10 years have body weights comparable to adult patients. According to the KONOS regulations of donor-recipient body weight match ratio of 1:2, livers from these pediatric donors can be allocated to adult recipients as whole or split liver grafts. To the best of our knowledge, there is no KONOS regulation for the allocation of pediatric 
liver allografts to pediatric recipients on priority.

In pediatric patients aged below 5 years, graft-recipient size matching to avoid large-for-size graft implantation is one of the major concerns. The main problems of largefor-size liver grafts include the risk of abdominal compartment syndrome due to the small abdominal cavity of the recipient, discrepancies in vessel size, and insufficient portal circulation and tissue oxygenation [6,7]. A 25-monthold pediatric recipient in the present study underwent graft size reduction through in situ resection of the left lateral section, reducing the GRWR from $7.2 \%$ to $6.2 \%$.

On the other hand, for adult and adolescent recipients, implantation of a small-for-size graft (e.g., living donor LT) can also be a matter of concern. In Taiwan, a 60-yearold woman with body weight of $56 \mathrm{~kg}$ received a whole liver graft with a GRWR of $0.46 \%$ from a 10 -year-old donor weighing $12.8 \mathrm{~kg}$ [2]. Such an extreme mismatch of graft and body weight is not permitted in Korea according to the KONOS regulations. In the present study, the mean GRWR was $2.08 \% \pm 0.48 \%$ in 16 pediatric-to-adult whole liver recipients and $1.62 \% \pm 0.29 \%$ in four pediatric-to-adult split liver recipients.

The incidence of vascular complications reported in the pediatric LT literature is variable and can be up to $25 \%-$ $33 \%$ [8-10]. Hepatic artery thrombosis is the most serious complication after LT and early hepatic artery thrombosis is the main cause of graft loss in pediatric LT. A similar incidence of early vascular complications was reported in the pediatric-to-pediatric LT group and in the pediatric-to-adult LT group [3]. Moreover, low body weight of the recipient was an independent risk factor for vascular complications in pediatric LT [3]. Vascular complications frequently occur following implantation of a whole liver graft in an infant recipient due to the small vessel size, even when the graft size is well matched with the recipient body size. We previously reported that portal vein complications occurred in four out of seven cases of infant-to-infant whole LT and these complications could be successfully prevented through customized surgical techniques with side-to-side unification venoplasty [11].

In the present study, the pediatric end-stage liver disease (PELD) scores in pediatric patients were much lower than the model for end-stage liver disease (MELD) scores in adult patients. Considering the characteristics of liver diseases in childhood, PELD scores in pediatric patients cannot be compared directly with MELD scores in adult patients in the current Korean setting. Severely abnormal liver function is not observed in many grave conditions that require LT in children. Inborn errors of metabolism such as urea cycle disorders or organic acidemia and hepatoblastoma are examples of such conditions [4]. Therefore, we suggest that liver allografts from pediatric donors aged $\leq 12$ years (age limit of PELD score) should be allocated to pediatric recipients on priority.

The Organ Procurement and Transplantation Network (OPTN) of North America clearly prioritizes potential pediatric transplant recipients while allocating livers from pediatric deceased donors [12]. The ethical principles behind their pediatric organ allocation policy are elucidated by the Pediatric Transplantation Committee and the Ethics Committee of the OPTN/United Network for Organ Sharing [13]. The National Organ Transplant Act charges the OPTN to recognize the differences in health and organ transplantation issues between children and adults throughout the system and to adopt criteria, policies, and procedures that address the unique health care needs of children.

The present study has several notable limitations. It was a retrospective, single-center study with a relatively small number of patients. The detailed allocation status of pediatric donors recorded in the KONOS database was not available. Further high-volume multicenter studies are necessary to validate the results of the present study.

In conclusion, the results of the present study suggested that more than half of the pediatric donor liver allografts were allocated to adult patients. It is necessary to revise the recipient criteria for the allocation of livers from deceased donors, especially those from pediatric donors, to address the special needs of children on the pediatric LT waiting list.

\section{ACKNOWLEDGMENTS}

\section{Conflict of Interest}

Shin Hwang is an editorial board member of the journal but did not involve in the peer reviewer selection, evaluation, or decision process of this article. No other potential conflicts of interest relevant to this article were reported.

\section{Funding/Support}

This study was supported by research grant from the Korean Society for Transplantation (2020-03-01003-005).

\section{ORCID}

Jung-Man Namgoong 


$\begin{array}{ll}\text { Shin Hwang } & \text { https://orcid.org/0000-0002-9045-2531 } \\ \text { Chul-Soo Ahn } & \text { https://orcid.org/0000-0002-3844-3646 } \\ \text { Ki-Hun Kim } & \text { https://orcid.org/0000-0002-4016-0995 } \\ \text { Deok-Bog Moon } & \text { https://orcid.org/0000-0002-8209-3540 } \\ \text { Tae-Yong Ha } & \text { https://orcid.org/0000-0001-9932-0212 } \\ \text { Gi-Won Song } & \text { https://orcid.org/0000-0002-4235-0434 } \\ \text { Dong-Hwan Jung } & \text { https://orcid.org/0000-0001-5984-023X } \\ \text { Gil-Chun Park } & \text { https://orcid.org/0000-0003-1631-3258 } \\ \text { Dae-Yeon Kim } & \text { https://orcid.org/0000-0001-6130-1796 } \\ \text { Kyung Mo Kim } & \text { https://orcid.org/0000-0001-7896-6751 } \\ \text { Seak Hee Oh } & \text { https://orcid.org/0000-0002-9672-8877 } \\ \text { Sung-Gyu Lee } & \text { https://orcid.org/0000-0001-9161-3491 }\end{array}$

\section{Author Contributions}

Conceptualization: SH. Data curation: DYK, KMK, SHO, SGL. Methodology: CSA, KHK, DBM, TYH, GWS, DHJ, GCP. Visualization: $\mathrm{SH}$. Writing-original draft: $\mathrm{SH}, \mathrm{JMN}$. Writing-review \& editing: $\mathrm{SH}$.

\section{REFERENCES}

1. Emre S, Soejima Y, Altaca G, Facciuto M, Fishbein TM, Sheiner PA, et al. Safety and risk of using pediatric donor livers in adult liver transplantation. Liver Transpl 2001;7:41-7.

2. Feng $A C$, Liao CY, Fan HL, Chen TW, Hsieh CB. A successful child-to-adult deceased donor liver transplantation: a case report and literature review. Ann Transplant 2015;20:21-4.

3. Zhang R, Zhu ZJ, Sun LY, Wei L, Qu W. Outcomes of liver transplantation using pediatric deceased donor livers: a single-center analysis of 102 donors. Chin Med J (Engl) 2018;131:677-83.

4. Lee S, Lee SK. Pediatric liver transplantation in Korea: long-term outcomes and allocations. J Korean Soc
Transplant 2019;33:1-5.

5. Hwang S, Kim DY, Namgoong JM, Kim KM, Oh SH, Kim $\mathrm{KH}$, et al. Living donor liver retransplantation for primary non-function of liver graft following multivisceral transplantation in a pediatric patient. Ann Hepatobiliary Pancreat Surg 2020;24:198-202.

6. Kiuchi T, Kasahara M, Uryuhara $\mathrm{K}$, Inomata $\mathrm{Y}$, Uemoto $\mathrm{S}$, Asonuma $\mathrm{K}$, et al. Impact of graft size mismatching on graft prognosis in liver transplantation from living donors. Transplantation 1999;67:321-7.

7. Vanatta JM, Esquivel CO. Status of liver transplantation in infants $<5 \mathrm{~kg}$. Pediatr Transplant 2007;11:5-9.

8. Heffron TG, Welch D, Pillen T, Fasola C, Redd D, Smallwood GA, et al. Low incidence of hepatic artery thrombosis after pediatric liver transplantation without the use of intraoperative microscope or parenteral anticoagulation. Pediatr Transplant 2005;9:486-90.

9. Shackleton CR, Goss JA, Swenson K, Colquhoun SD, Seu P, Kinkhabwala MM, et al. The impact of microsurgical hepatic arterial reconstruction on the outcome of liver transplantation for congenital biliary atresia. Am J Surg 1997;173:431-5.

10. Ooi CY, Brandão LR, Zolpys L, de Angelis M, Drew W, Jones $\mathrm{N}$, et al. Thrombotic events after pediatric liver transplantation. Pediatr Transplant 2010;14:476-82.

11. Namgoong JM, Hwang S, Ahn CS, Jung DH, Park GC. Side-to-side portal vein reconstruction for infant-to-infant deceased donor whole liver transplantation: report of 2 cases with video. Ann Hepatobiliary Pancreat Surg 2020;24:301-4.

12. United Network for Organ Sharing (UNOS). Organ distribution: allocation of livers [Internet]. Richmond, VA: UNOS; 2011 [cited 2020 Jun 30]. Available from: https://optn.transplant.hrsa.gov.

13. United Network for Organ Sharing (UNOS). Ethical principles of pediatric organ allocation [Internet]. Richmond, VA: UNOS; 2011 [cited 2020 Jun 30]. Available from: https://optn.transplant.hrsa.gov. 